\title{
The Nature of the Sensory Input to the Neonatal Rat Barrel Cortex
}

\author{
(DDinara Akhmetshina, ${ }^{1 \star}$ Azat Nasretdinov, ${ }^{1 \star}$ Andrei Zakharov, ${ }^{1}{ }^{\mathbb{C}}$ Guzel Valeeva, ${ }^{1 \star}$ and ${ }^{\circ}$ Roustem Khazipov ${ }^{1,2,3}$ \\ ${ }^{1}$ Laboratory of Neurobiology, Kazan Federal University, Kazan 420008, Russia, ${ }^{2}$ INMED/INSERM U901, Marseille 13273, France, and ${ }^{3}$ Aix-Marseille \\ University, Marseille 13273, France
}

Sensory input plays critical roles in the development of the somatosensory cortex during the neonatal period. This early sensory input may involve: (1) stimulation arising from passive interactions with the mother and littermates and (2) sensory feedback arising from spontaneous infant movements. The relative contributions of these mechanisms under natural conditions remain largely unknown, however. Here, we show that, in the whisker-related barrel cortex of neonatal rats, spontaneous whisker movements and passive stimulation by the littermates cooperate, with comparable efficiency, in driving cortical activity. Both tactile signals arising from the littermate's movements under conditions simulating the littermates' position in the litter, and spontaneous whisker movements efficiently triggered bursts of activity in barrel cortex. Yet, whisker movements with touch were more efficient than free movements. Comparison of the various experimental conditions mimicking the natural environment showed that tactile signals arising from the whisker movements with touch and stimulation by the littermates, support: (1) a twofold higher level of cortical activity than in the isolated animal, and (2) a threefold higher level of activity than in the deafferented animal after the infraorbital nerve cut. Together, these results indicate that endogenous (self-generated movements) and exogenous (stimulation by the littermates) mechanisms cooperate in driving cortical activity in newborn rats and point to the importance of the environment in shaping cortical activity during the neonatal period.

Key words: barrel; development; EEG; neonate; whisker

\section{Significance Statement}

Sensory input plays critical roles in the development of the somatosensory cortex during the neonatal period. However, the origins of sensory input to the neonatal somatosensory cortex in the natural environment remain largely unknown. Here, we show that in the whisker-related barrel cortex of neonatal rats, spontaneous whisker movements and passive stimulation by the littermates cooperate, with comparable efficiency, in driving cortical activity during the critical developmental period.

\section{Introduction}

Sensory input plays critical roles in the development of the primary somatosensory S1 cortex (for review, see Erzurumlu and Gaspar, 2012; Luhmann et al., 2016; Tiriac and Blumberg, 2016). In the whisker-related barrel cortex, the whisker-barrel map forms during the first postnatal week through the elaboration of

\footnotetext{
Received May 31, 2016; revised July 14, 2016; accepted Aug. 7, 2016.

Author contributions: G.V. and R.K. designed research; D.A., A.N., and G.V. performed research; D.A., A.N., and A.Z. analyzed data; G.V. and R.K. wrote the paper.

This work was supported by INSERM LIA to R.K., Grant to Leading Scientists 11.G34.31.0075 to R.K., the program of competitive growth of Kazan Federal University, and the subsidy allocated to Kazan Federal University for the state assignment in the sphere of scientific activities. We thank Drs. Heiko Luhmann and Mark S. Blumberg for helpful suggestions and comments on the manuscript; Dr. Marat Minlebaev, Maxim Mukhtarov, and Iskander Askarov for advice and assistance in data analysis; and David Jappy for editing the manuscript.

The authors declare no competing financial interests.

*D.A., A.N., and G.V. contributed equally to this study.

Correspondence should be addressed to Dr. Roustem Khazipov INMED/INSERM U901, 163 Avenue de Luminy, Marseille 13273, France. E-mail: roustem.khazipov@inserm.fr.

DOI:10.1523/JNEUROSCI.1781-16.2016

Copyright $\odot 2016$ the authors $\quad 0270-6474 / 16 / 369922-11 \$ 15.00 / 0$
}

thalamocortical connections and involving transient circuits, including the subplate (Higashi et al., 2005; Kanold and Luhmann, 2010; Hoerder-Suabedissen and Molnar, 2015). This is also the critical period for barrel map plasticity. Indeed, sensory deprivation during the early postnatal period results in morpho-functional malformations in the S1 barrel map (Van der Loos and Woolsey, 1973; Simons and Land, 1987; Fox, 1992; Crocker-Buque et al., 2015) and causes deficits in whisker-dependent behaviors (Carvell and Simons, 1996). During this period, the barrel cortex displays enhanced plasticity at thalamocortical synapses (Isaac et al., 1997; Feldman and Knudsen, 1998; Feldman and Brecht, 2005; An et al., 2012) and expresses unique spontaneous and sensory-driven activity patterns that are thought to participate in the activitydependent formation of the topographic thalamocortical barrel maps (Yang et al., 2009, 2013; Minlebaev et al., 2011). Therefore, it is important to determine the mechanisms, which provide sensory activation of the somatosensory cortex during the neonatal period. 
The existing knowledge about the somatosensory cortex functions and about the properties of sensory-evoked responses in neonatal rodents is mainly based on studies using headrestrained isolated newborn pups (Khazipov et al., 2004; Yang et al., 2009; Blumberg et al., 2015). It has been shown that neuronal network activity in the somatosensory cortex of a newborn has a discontinuous temporal organization, and it is characterized by intermittent bursts of activity organized in the spindle and $\gamma$ oscillations that are separated by long, up to tens of seconds, periods of silence (Khazipov et al., 2004; Minlebaev et al., 2007, 2009, 2011; Yang et al., 2009, 2013). These activity bursts can occur spontaneously and persist (although at lower frequency) after sensory deafferentation (Khazipov et al., 2004; Yang et al., 2009), and they can also be efficiently evoked by somatosensory stimulation. In the natural nesting conditions, such external stimulation could be provided by the mother and littermates. Another potential source of sensory stimulation is sensory feedback from spontaneous myoclonic twitches and startles, which are characteristic movement patterns in the neonates, triggering activity bursts in the somatosensory thalamus and cortex (Khazipov et al., 2004; Mohns and Blumberg, 2010; Tiriac et al., 2012). Sensory feedback from movements may involve the following: (1) proprioceptive and reafferent signals in the case of free movements and (2) additional ex-afferent (touch-generated) signals in the case of movements accompanied by tactile contact (Moore et al., 2015). Thus, a total sensory input to the neonatal S1 cortex in natural conditions may involve self-generated movements of the newborn rat, as well as passive stimulation provided by the littermates and mother. However, how the somatosensory cortex operates in a naturalistic environment, and what the relative contributions of different sensory stimuli in driving the S1 activity in neonate are remains largely unknown.

In this study, we have attempted to differentiate these mechanisms in the whisker-barrel system of newborn rats by using simultaneous video recordings of whisker movements and recordings of electrical activity in the respective cortical barrels under various conditions mimicking a natural environment. Our main finding is that the sensory feedback from the self-generated whisker movements and the passive stimulation by the littermates cooperate, with a comparable efficacy, in driving cortical activity in the newborn rats.

\section{Materials and Methods}

\section{Ethical approval}

This work has been performed in accordance with EU Directive 2010/ 63/EU for animal experiments, and all animal-use protocols were approved by the French National Institute of Health and Medical Research (INSERM, protocol N007.08.01) and Kazan Federal University on the use of laboratory animals (ethical approval by the Institutional Animal Care and Use Committee of Kazan State Medical University N9-2013).

\section{Surgery}

Wistar rats of both sexes from postnatal days (P) 1-7 were used. Preparation of the animals for head-restrained recordings was as described previously (Khazipov et al., 2004; Minlebaev et al., 2011) with some modifications. In brief, under isoflurane anesthesia, the skull of the animal was cleaned of skin and periosteum and covered by dental cement (Grip Cement, Caulk Dentsply), leaving a $5 \mathrm{~mm}$ window above the barrel cortex. The wound was treated with xylocaine $(2 \%)$ and chlorhexidine $(0.05 \%)$, animals were warmed, left for an hour to recover from anesthesia and returned to the litter. Recordings from the head-restrained nonanesthetized rats were performed 1 or $2 \mathrm{~d}$ after surgery. A metal ring was fixed to the skull by dental cement and via a ball-joint to a magnetic stand. Animals were surrounded by a cotton nest and heated via a ther- mal pad $\left(35^{\circ} \mathrm{C}-37^{\circ} \mathrm{C}\right)$. A chlorided silver wire, placed in the cerebellum or visual cortex, served as a ground electrode.

Transection of the infraorbital nerve was performed under deep isoflurane anesthesia at the level of the infraorbital foramen.

\section{Sensory stimulation}

For mechanical whisker stimulation, the whiskers were trimmed to a length of $0.8-1.5 \mathrm{~mm}$. The tip of the whisker was inserted $0.5 \mathrm{~mm}$ into the blunt tip of a needle glued to the end of piezo actuator. To induce deflection of the piezo actuator, square $30-40 \mathrm{~V}$ pulses of 2 or $10 \mathrm{~ms}$ duration were applied at 10-20 s intervals.

The experiments with facial nerve stimulation were performed in urethane-anesthetized rat pups ( $1.5 \mathrm{~g} / \mathrm{kg}$, i.p.). The ramus buccolabialis superior (a branch of the facial nerve) was exposed by a 1- to 2-mm-long incision above the middle part of the ramus buccolabialis superior and stimulated by bipolar electrodes at a frequency of $0.1-0.2 \mathrm{~Hz}$, the stimulus amplitude and duration were selected individually for each animal and did not exceed $50 \mathrm{~V}$ and $2 \mathrm{~ms}$, respectively.

\section{Electrophysiology}

Extracellular recordings of the local field potential (LFP) and multiple unit activity (MUA) were performed from a barrel column using linear silicone probes (16 channels, 25 or $50 \mu \mathrm{m}$ separation distance; Neuronexus Technologies). A hole was drilled in the skull above the barrel cortex (anteroposterior -0.3 to $-1.2 \mathrm{~mm}$; lateral $3-4 \mathrm{~mm}$ from bregma). Electrodes were vertically inserted at a depth of $680-1100 \mu \mathrm{m}$ from the cortical surface. The signals were amplified and filtered $(\times 10,000 ; 0.1 \mathrm{~Hz}$ to $10 \mathrm{kHz})$ using a DigitalLynx (Neuralynx) amplifier, digitized at $32 \mathrm{kHz}$, and saved on a PC for post hoc analysis.

Raw data were preprocessed using custom-written functions in MATLAB (The MathWorks). The recordings were first explored to detect MUA, following which the raw data were downsampled to $1 \mathrm{kHz}$. MUA was detected as negative events exceeding 3.5 SDs of the baseline in a $300-4000 \mathrm{~Hz}$ band-passed signal. Analysis of units and LFP was performed using custom-written MATLAB-based programs and Chronux toolbox (Mitra and Pesaran, 1999). Data from 1 or 2 recording channels located in layer 4 were used for LFP and MUA analysis unless indicated. Current source density (CSD) analysis was used to eliminate volume conduction and localize synaptic currents. CSD was computed for each recording site according to a differential scheme for the second derivative and smoothed with a triangular kernel of length 3 (Freeman and Nicholson, 1975). The number of units associated with sensory-evoked potential (SEP) was counted within the time window of $\pm 25 \mathrm{~ms}$ from the SEP peak. MUA during a burst was estimated within a time window from 25 to $700 \mathrm{~ms}$ after the SEP peak, spindle burst oscillation power was determined within a time window from 25 to $400 \mathrm{~ms}$ after the SEP peak. Spectral analysis was performed using the Chronux toolbox. Spectral power was estimated using direct multitaper estimators $(5 \mathrm{~Hz}$ bandwidth, 3 tapers, $200 \mathrm{~ms}$ spectral window) or continuous wavelet transformation with a Morlet wavelet of the $8-100 \mathrm{~Hz}$ bandpass filtered LFP signal.

\section{Video recordings}

Whisker movements. Gouache paint was applied to the trimmed tips of the principal whisker (PW) and neighboring whiskers. One or two additional gouache marks were made on the whisker pad skin to serve as reference points. A high speed digital camera (Promon 501, AOS Technologies) with a TEC-M55 objective (Computar) was placed along the $\mathrm{PW}$ axis to record whisker movements at $100 \mathrm{frames} / \mathrm{s}$ and $480 \times 320$ resolution in two consecutive 15-min-long recordings. The analysis of the video recordings was performed using ProAnalyst 1.5.7.4 (Xcitex). The coordinates of the gouache mark on the whisker pad were subtracted from the coordinates of the observed whisker and filtered $(>0.1 \mathrm{~Hz}$ median filter). Whisker movements were detected as events exceeding a threshold of 3.5 SDs calculated through the trace length. If the time window between two detected events was $<1 \mathrm{~s}$, they were considered to be one continuous movement. PW contact with the external objects was detected from a difference in the coordinates of the PW and the neighboring whisker in the same row.

Pup movements. The littermate was cotton wrapped and positioned closely $(\leq 3 \mathrm{~mm}$ ) to the head-restrained recorded rat pup (see Fig. $4 A$ ) 
A

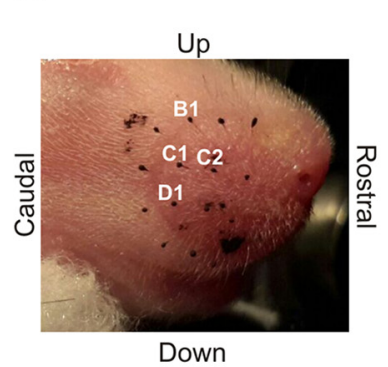

B

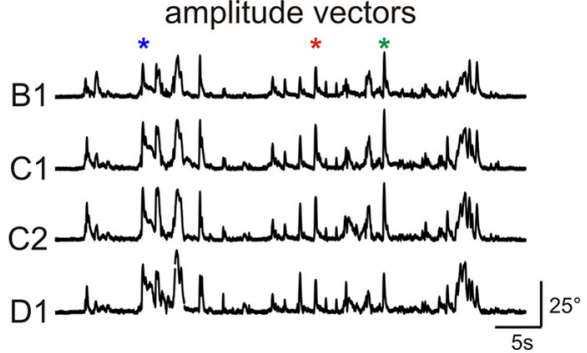

C Whisker movement cross-correlation

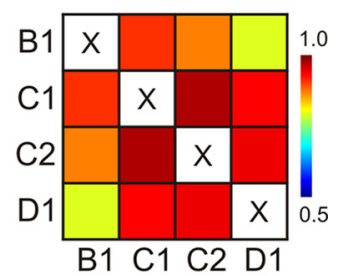

E Movement direction

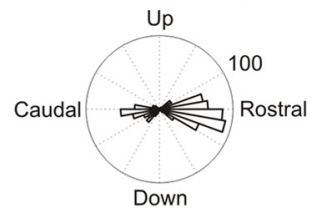

F Movt amplitudes

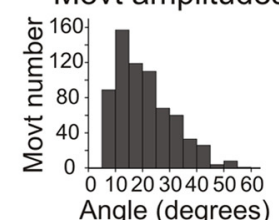

Figure 1. Whisker movement patterns in neonatal rats. $\boldsymbol{A}$, Snapshot of a $\mathrm{P} 5$ rat snout with the whisker tips marked with a black paint. Example trace $(\boldsymbol{B})$ and cross-correlation coefficients $(\boldsymbol{C})$ of movement of the four whiskers labeled on $\boldsymbol{A}$. $\boldsymbol{D}$, Time-colored traces of the whisker movements marked with asterisks on $\boldsymbol{B}$. Gray circles represent the whisker bases. $\boldsymbol{E}$, $\boldsymbol{F}$, Histograms of whisker movement direction $(\boldsymbol{E})$ and angular amplitude $(\boldsymbol{F})$. Pooled data from 10 nonanesthetized P2-P7 rat pups (in total 675 movements).

and their movements were recorded with Promon 501 and QICAM Fast 1394 (QImaging) digital cameras. The line (1-D) method was used to detect the movements of the whisker pad region of each pup using the parameters as described above for whisker motion analysis.

\section{Pups behavior in the nest}

The observation of the pup's interactions with the littermates, mother, and passive objects in the nest was performed using a C270 (Logitech) camera with $3 \mathrm{~h} / \mathrm{d}$ video recordings of 1 or 2 rat pups per nest in their home cage in the habitual environment of the animal house ( $n=6$ nests, $8-12$ rat pups per nest; $\mathrm{P} 0-\mathrm{P} 5)$.

\section{Statistics}

Statistical analysis was performed using the MATLAB Statistics toolbox. Statistical comparisons between the groups were performed using the Wilcoxon signed-rank and Mann-Whitney tests. The significance level was set at $p<0.05$. Group data are expressed as mean \pm SEM unless otherwise indicated.

\section{Results}

\section{Whisker movement patterns in neonatal rats}

Spontaneous whisker movements occurring in behaving animals and their relationships with electrical activity in the whiskerrelated barrel cortex were examined in nonanesthetized headrestrained postnatal day $\mathrm{P} 2-\mathrm{P} 7$ rat pups using high-speed video recordings. To detect the active whisker movements and to exclude their passive displacement resulting from entire mistacial pad movements, trajectories of the marks placed on the skin near the PW were subtracted from the whisker trajectories. Although we did not observe any rapid active whisking (which emerges starting from the second postnatal week), whisker movements in the neonatal rats were characterized by a variety of the primitive intermittent active whisker movement patterns that is in keeping with previous studies (Welker, 1964; Landers and Philip, 2006; Grant et al., 2012; Tiriac et al., 2012) (Fig. 1). Whisker movements occurred at average rate of $2.4 \pm 0.2$ movements per min- ute ( $n=10$ pups; P2-P7), and their vast majority were collective synchronized whisker movements when all or groups of whiskers moved in unison as evidenced by cross-correlation analysis and occurring (Fig. $1 B-D$ ). Although there was a tendency in the developmental increase at the whisker movement frequency and amplitude from P2 to P7, this was not significant, however. The highest correlation coefficient of movements was observed between the neighboring whiskers within a row $(0.985 \pm 0.003$; $n=10$ pups; P2-P7; Fig. $1 C$ ). Movements were mainly oriented in two directions: protraction (Rayleigh vector angle $-4.3 \pm$ $21.0^{\circ}$ [mean $\pm \mathrm{SD} ; 0^{\circ}=$ rostral direction] and Rayleigh vector amplitude $21.5 \pm 10.7^{\circ}$ ), and retraction (angle 194.0 $\pm 24.4^{\circ}$, amplitude $19.3 \pm 9.2^{\circ} ; n=10$ pups; P2-P7; Fig. $\left.1 E, F\right)$. The duration of whisker movements was variable, with the main contribution of the short-duration unidirectional (preferentially retraction or protraction) events illustrated by the example movements marked in Figure $1 B, D$ (green and red asterisks), and longer-lasting movements with complex trajectories as illustrated by the example trace marked by Figure $1 B, D$ (blue asterisk). Thus, the movement patterns in the neonatal rat pups share some similarities with the movement patterns in adult animals, including the predominance of collective movements in the protraction-retraction direction (Welker, 1964; Bermejo et al., 2002; Hill et al., 2008). However, the neonatal whisker movements are not yet organized in active whisking (see also Welker, 1964; Landers and Philip, 2006; Grant et al., 2012) and include primitive intermittent patterns of brief twitchy events and more complex movements (Tiriac et al., 2012), which are also observed in the skeletal musculature during the neonatal period (Gramsbergen et al., 1970; Khazipov et al., 2004; Tiriac et al., 2015). We further explored how these primitive whisker movements correlate with the activity in the primary somatosensory barrel cortex. 
A
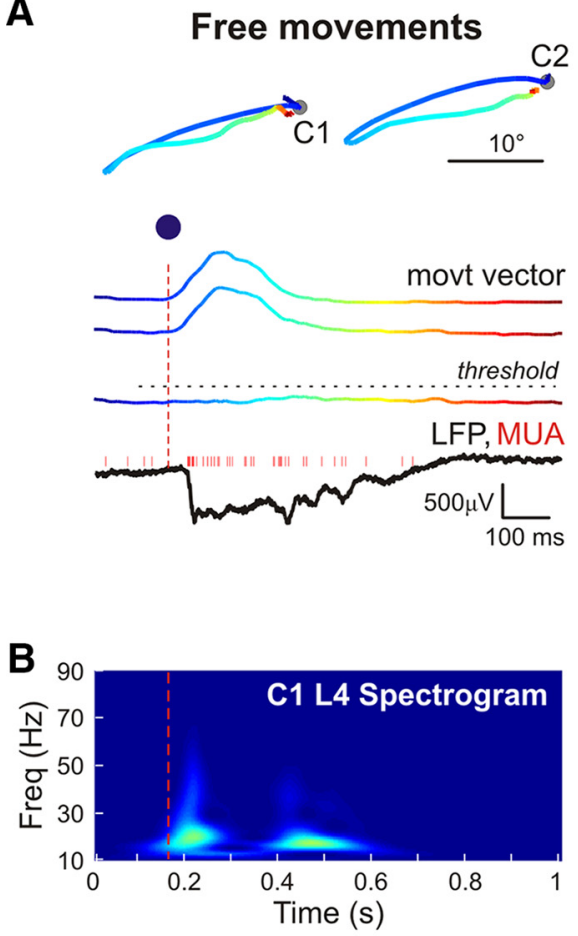

Active Touch

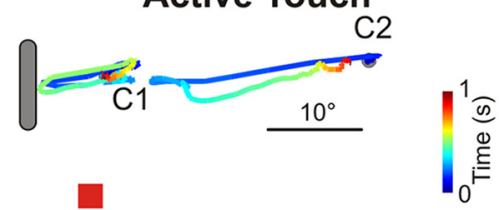

C2

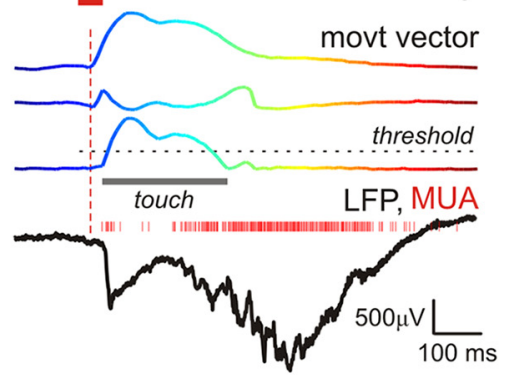

$(\mathrm{C} 1-\mathrm{C} 2)$

C1 L4

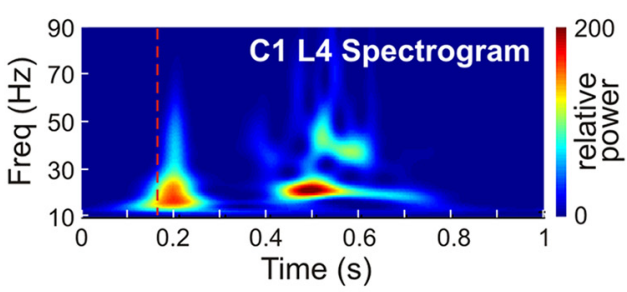

C

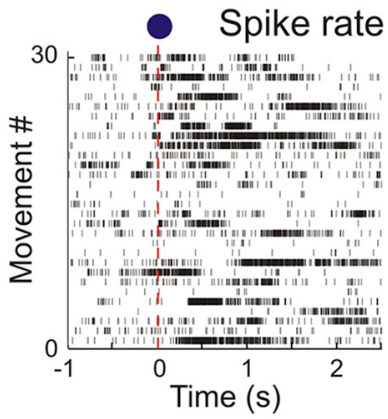

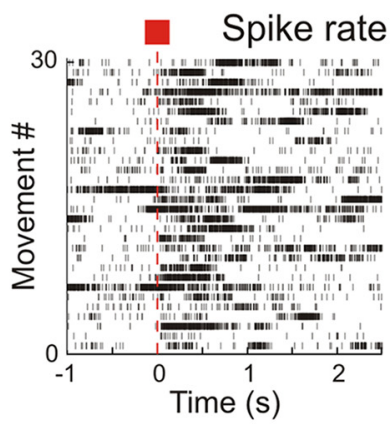

D

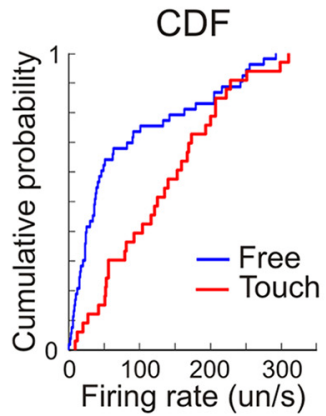

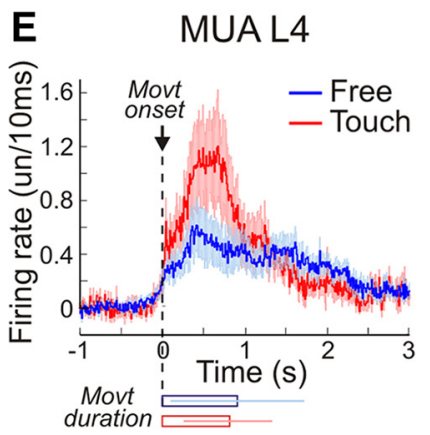
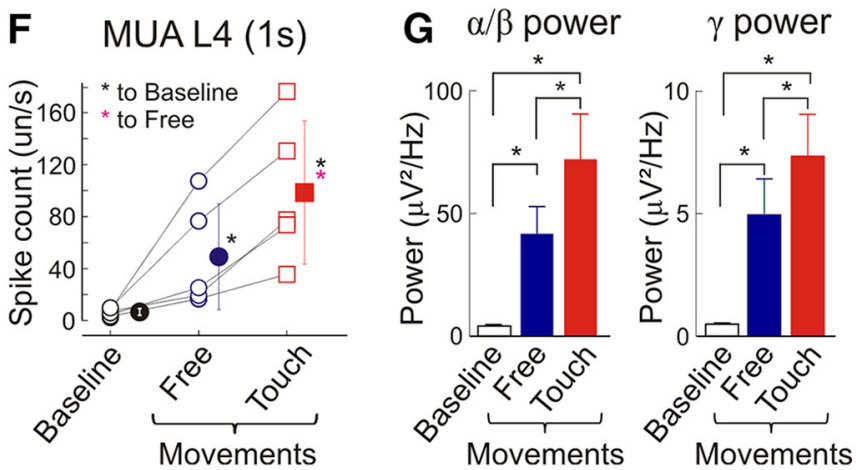

Figure 2. Activity in a cortical barrel of a neonatal rat during free principal whisker movements and active touch. $A$, The color-coded example traces of caudally directed free movement of $(1$ and C2 whiskers (top left) and a movement associated with C1 whisker contact with an external object (top right) obtained from a P4 nonanesthetized rat pup. Bottom, Corresponding movement amplitude vectors and the result of their subtraction $(\triangle C 1-C 2)$. The color encodes the time between the movement onset and the end. Bottom, Simultaneous LFP (black traces) and MUA (red bars) recordings from $L 4$ of $C 1$ barrel column. Vertical dashed lines indicate movement onsets. $\boldsymbol{B}$, Corresponding wavelet LFP spectrograms from $L 4$ of the $C 1$ cortical barrel column. $C, D$, Caudal $C 1$ whisker movement-triggered $(1 \mathrm{~L} 4$ layer $(\boldsymbol{C})$ spike raster plots and $(\boldsymbol{D})$ cumulative distribution of spikes detected within $1 \mathrm{~s}$ after $(1$ movement onset. $\boldsymbol{E}-\mathbf{G}$, Group data from five nonanesthetized $P 4-P 7$ rats on the $(\boldsymbol{E})$ spike firing rate $(\boldsymbol{F})$ total spike counts and $(\boldsymbol{G}) \mathrm{LFP}$ power in $\alpha / \beta$ and $\gamma$ frequency bands in $L 4$ of principal barrel column evoked by free PW movements and movements with touch. Baseline MUA and LFP power was assessed within $1 \mathrm{~s}$ of baseline average. ${ }^{*} p<0.05$.

Cortical activation during whisker movements

Extracellular multichannel silicone probe recordings across layers were obtained from a cortical barrel column, and the LFP and MUA were correlated with the PW movements in two experi- mental configurations: (1) free whisker movements in air and (2) movements with touch, when an object was placed into the PW trajectory (Fig. 2A). The PW was identified on the basis of the maximal SEP and short latency L4 MUA followed by early $\gamma$ 
oscillations and spindle bursts in response to a brief mechanical deflection (Minlebaev et al., 2011; Yang et al., 2013; Mitrukhina et al., 2014). Both types of whisker movements triggered, although with different efficacy, population MUA bursts associated with rapid oscillations nested in the envelope of $\delta$ waves with a maximal LFP power and MUA response in L4 (Movies 1, 2), as evidenced by the wavelet analysis and spike raster plots triggered by the movement onset (Fig. $2 B, C$ ). The cortical activity was more robust when it occurred during movements with touch than during free movements: (1) the proportion of movements associated with cortical bursts was higher during movements with touch $(85 \pm 7.5 \%)$ than during free movements $(56.5 \pm 6.6 \%$; $n=$ 10 pups; P2-P7); (2) during free movements, L4 MUA increased from $6.6 \pm 2.8$ spikes/s of baseline activity to $49.1 \pm 40.1$ spikes/s within a $1 \mathrm{~s}$ time window after the movement onset; movements with touch were associated with an almost twofold stronger increase to $98.5 \pm 55.1$ spikes $/ \mathrm{s}$ ( $n=5$ pups; P4-P7; $p=0.031$; paired sample Wilcoxon signed rank test; Fig. $2 D-F)$; and (3) similarly, LFP power in the spindle burst $(8-29 \mathrm{~Hz})$ and gamma $(30-90 \mathrm{~Hz})$ frequencies showed an increase during free movements to $41.6 \pm$ $11.1 \mu \mathrm{V}^{2} / \mathrm{Hz}$ and $4.9 \pm 1.3 \mu \mathrm{V}^{2} / \mathrm{Hz}$, respectively, whereas during movements with touch, it attained $71.9 \pm 18.5$ $\mu \mathrm{V}^{2} / \mathrm{Hz}$ (spindle bursts) and $7.3 \pm 1.7$ $\mu \mathrm{V}^{2} / \mathrm{Hz}(\gamma)(n=5$ pups; $\mathrm{P} 4-\mathrm{P} 7 ; p=$ 0.031 ; paired sample Wilcoxon signed rank test; Fig. 2G). To estimate the impact of tactile contact during whisker movements on the total ongoing activity in the barrel cortex, we compared the mean L4 MUA from $30 \mathrm{~min}$ recording sessions of free whisker movements with $30 \mathrm{~min}$ recording sessions of whisker movements in continuous contact with various naturalistic passive objects. As naturalistic passive objects artificial fur, a mesh or an anesthetized littermate were presented. We found that overall the L4 MUA increases from $10.9 \pm 1.8$ spikes/s during free whisking to $13.3 \pm 2.2$ spikes/s during continuous contact with the passive objects ( $n=4$ pups; P2-P6; $p=0.029$; Wilcoxon rank sum test; all passive objects pooled together).

To provide accurate whisker movement control, which is difficult in behaving animals, we induced artificial muscle-driven whisker movements in anesthetized rat pups by applying electrical stimulation to the facial motor nerve (Fig. 3A,B) (Zucker and Welker, 1969; Szwed et al., 2003). Arti-

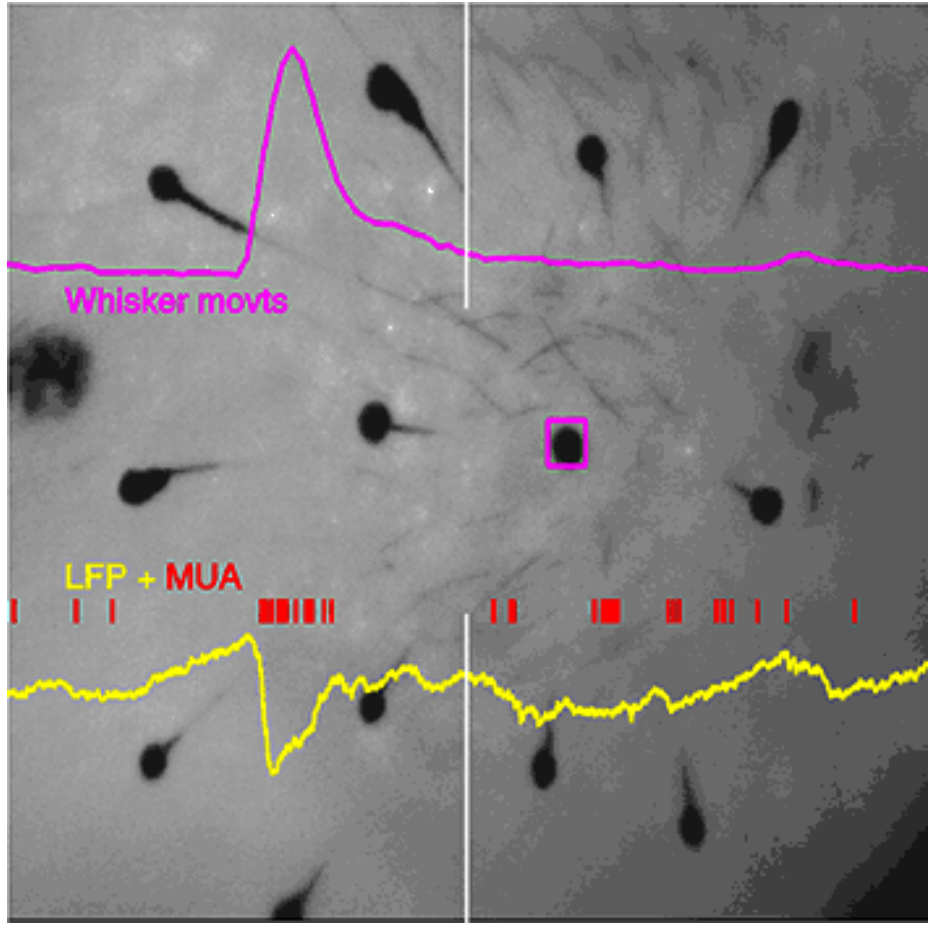

Movie 1. Example of a brief free whisker protraction movement and activity in the corresponding barrel. Magenta box represents $\mathrm{C} 1$ whisker tip position. Magenta trace represents $\mathrm{C} 1$ whisker movement vector amplitude. Yellow trace below represents LFP. Red vertical bars (and audio clicks) represent MUA in C1 barrel. White vertical line indicates the current frame. Recordings from a P6 rat. Video is displayed at $50 \mathrm{fps}$ frame rate (slowed down twofold).

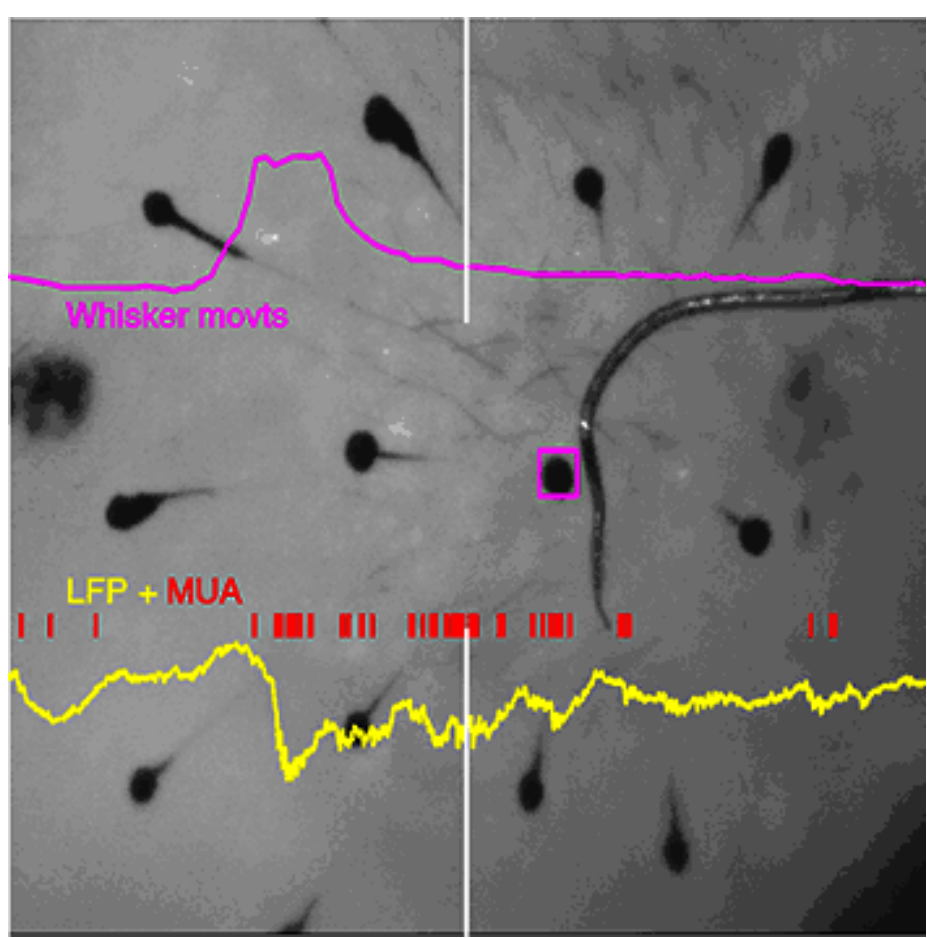

Movie 2. Example of a brief whisker protraction movement with touch and activity in the corresponding barrel. Magenta box represents C1 whisker tip position. Magenta trace represents C1 whisker movement vector amplitude. Yellow trace below represents LFP. Red vertical bars (and audio clicks) represent MUA in C 1 barrel. White vertical line indicates the current frame. Recordings from a P6 rat. Video is displayed at 50 fps frame rate (slowed down twofold). 
A
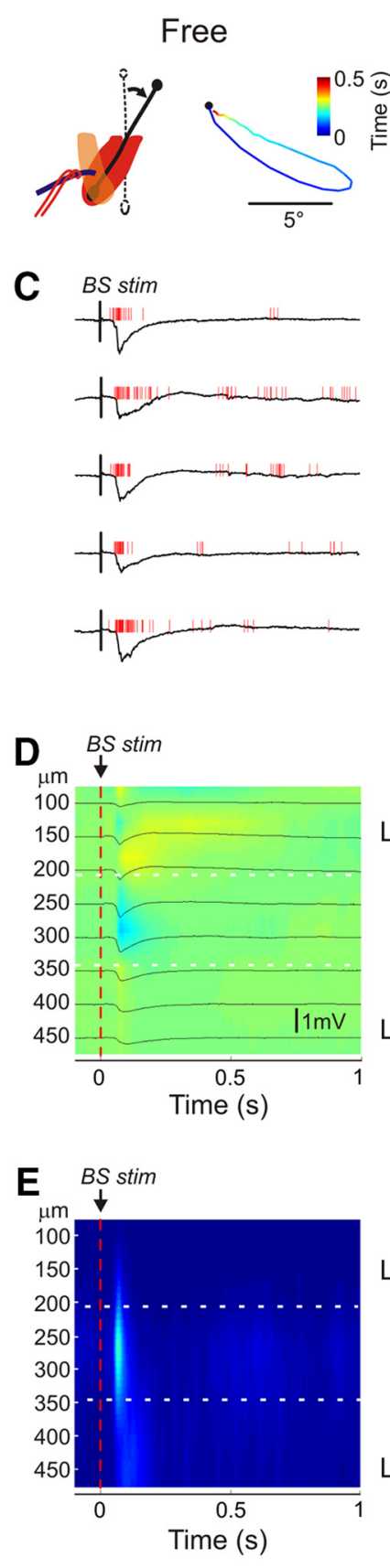

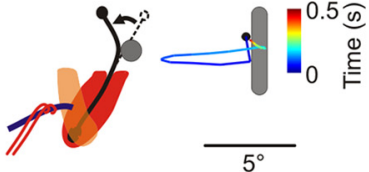

BS stim

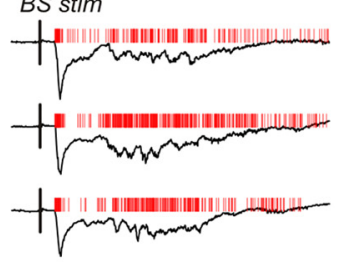

+7 montin
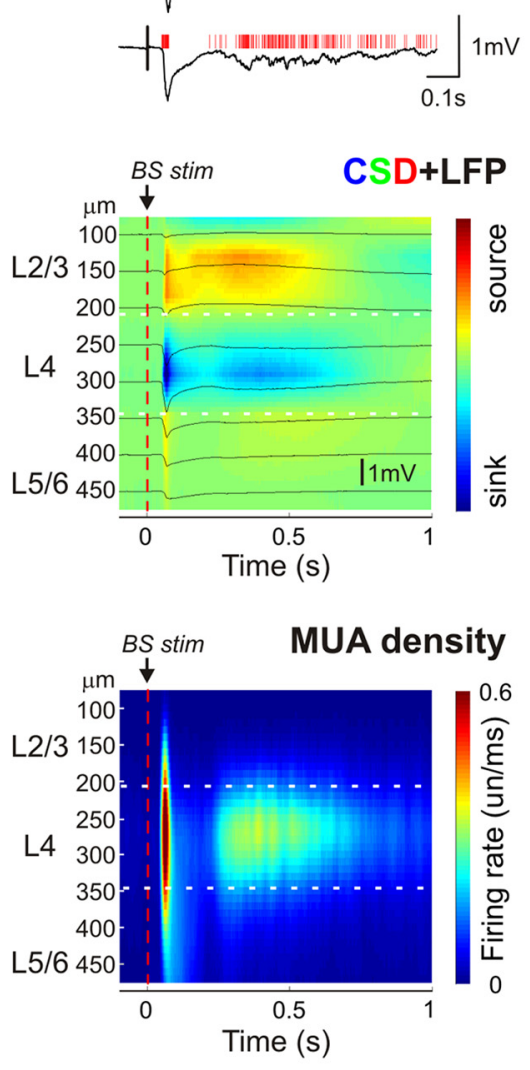

B

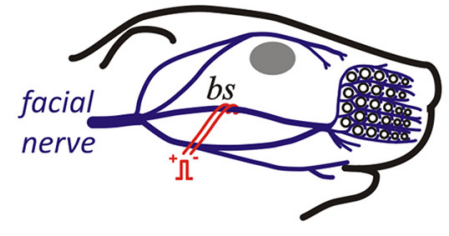

$\mathbf{F}$
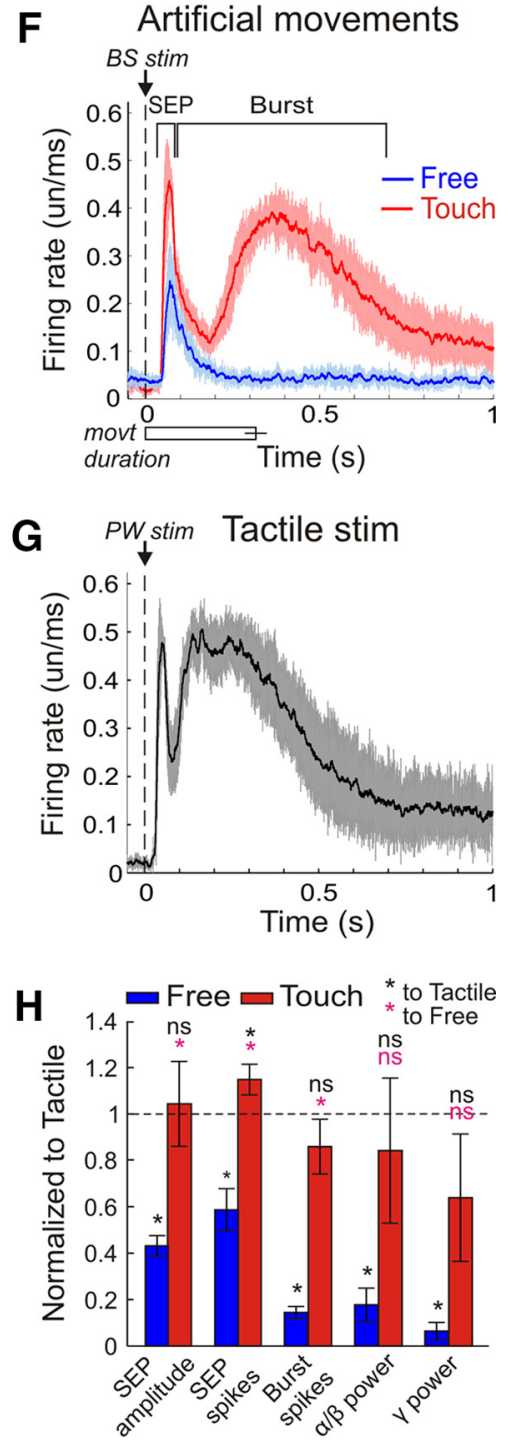

Figure 3. Cortical activity in the principal barrel column during artificial whisker movements. $\boldsymbol{A}$, Schematic drawing of motor facial nerve stimulation evoked protractions: (left) free and (right) with an object introduced in the whisker path and corresponding examples of time color-coded D2 whisker movement trajectories in a urethane-anesthetized P6 rat. $\boldsymbol{B}$, Schematic drawing of electrodes placement for stimulation of the middle branch (BS, ramus buccolabialis superior) of the facial nerve. $C$, Example responses evoked by artificial whisker movements in $L 4$ of the $D 2$ cortical barrel column. $\boldsymbol{D}$, The stimulus-triggered averages $(n=100)$ of LFP (black traces) overlaid on color-coded CSD plot and (E) MUA peristimulus time histograms across layers. $\boldsymbol{F}$ - $\boldsymbol{H}$, Statistical plots of $(\boldsymbol{F})$ L4 MUA peristimulus time histograms during free and touching artificial movements (SEP) and $(\boldsymbol{G})$ brief PW deflection, and $(\boldsymbol{H})$ parameters of the artificial whisker movement-evoked responses in the cortical L4 normalized to the PW deflection-evoked responses. $\boldsymbol{F}-\boldsymbol{H}$, Pooled data from four urethane-anesthetized P5-P6 rats. ${ }^{*} p<0.05$. ns, Not significant.

ficial whisker movements were composed of active protraction (angle $1.2 \pm 22.2^{\circ}$, amplitude $20.6 \pm 9.9^{\circ} ; n=4$ pups; P5-P6) and passive retraction (Fig. $3 A$, left). When an object was introduced into the whisker trajectory, the whisker touched it and bent so that the whisker tip moved in a backward direction, and then bent back and retracted (Fig. $3 A$, right). Free artificial movements evoked an SEP of $311 \pm 65 \mu \mathrm{V}$ with a delay of $47 \pm 8 \mathrm{~ms}$ after the stimulus with the main sink and a MUA burst of $10 \pm 3$ spikes/response in L4, but they barely evoked $\gamma /$ spindle bursts $(n=4$ pups; P4-P7; Fig. $3 C-F$;
Movie 3). When an object was introduced into the PW's path, artificial whisker movements evoked an almost twofold larger SEP of $750 \pm 168 \mu \mathrm{V}$ and associated L4 MUA of $17 \pm 2$ spikes/response (Fig. 3C-F; Movie 4). Artificial movements with touch much more reliably triggered the $\gamma /$ spindle burst component than free movements as evidenced by an increase in L4 MUA determined within a time window from 25 to $700 \mathrm{~ms}$ after SEP $(161 \pm 22$ vs $30 \pm 7$ spikes/response), and power of gamma $\left(25 \pm 15 \mathrm{vs} 3 \pm 2 \mu \mathrm{V}^{2} / \mathrm{Hz}\right)$ and spindle burst oscillations $\left(247 \pm 140\right.$ vs $\left.56 \pm 36 \mu \mathrm{V}^{2} / \mathrm{Hz}\right)$ as 
determined within a time window from 25 to $400 \mathrm{~ms}$ after SEP (Fig. 3C-F,H). We further compared the responses evoked by artificial whisker movements with the responses to brief mechanical deflection of the stationary passive PW, with the stimulus intensity evoking an SEP of the same amplitude as during artificial whisker movements with touch. The afterdischarge properties of these purely tactile-induced responses were largely similar to the responses evoked by the artificial whisker movements with touch including the magnitude of L4 MUA (204 \pm 46 spikes/response) and the power of spindle burst $\left(345 \pm 163 \mu \mathrm{V}^{2} / \mathrm{Hz}\right)$ and $\gamma(37 \pm$ $8 \mu \mathrm{V}^{2} / \mathrm{Hz}$ ) oscillations (Fig. $3 G, H$ ). The only difference between the external touch and artificial movement with touch evoked responses was a longer afterdischarge delay in the case of artificial movements with touch that may be due to more synchronous activation of sensory afferents during external mechanical deflection (Fig. $3 F, G$ ). After facial nerve dissection distal to the stimulation site, artificial whisker movements and cortical responses were completely suppressed ( $n=2$ pups), indicating that the stimulated nerve was purely motor. Together, the results obtained during spontaneous and artificially evoked movements indicate that the sensory feedback resulting from the free whisker movements and movements with tactile contact is an efficient source of cortical activation in neonatal rats, but also that movements with contact of passive objects are more effective than free whisker movements.

\section{Cortical activation by the littermate movements}

Passive tactile stimulation provided by the littermate and mother movements is another potential source of somatosensory input. Before electrophysiological recordings, we estimated the amount of time the rat pups spent with their snout in contact with the littermates and mother. Video recordings of the rat pup behavior in their home cage environment revealed that the rat pups spend $74 \pm 6 \%$ of their time in the nest with the whisker pad in a close contact with the littermates and mother. The mother rat left the nest for $6 \pm 2 \mathrm{~min}$ with $19 \pm 5$ min intervals $(21 \pm 5 \%$ of total recordings time). During these periods, the rat pups mainly stayed in contact with each other. Feeding periods of $27 \pm 5$ min occurred with $17 \pm 4$ min intervals (56 $\pm 6 \%$ of the time mothers spent in contact with the pups). During feeding, the pups' whiskers were continuously in contact with the mothers' fur. In total, the

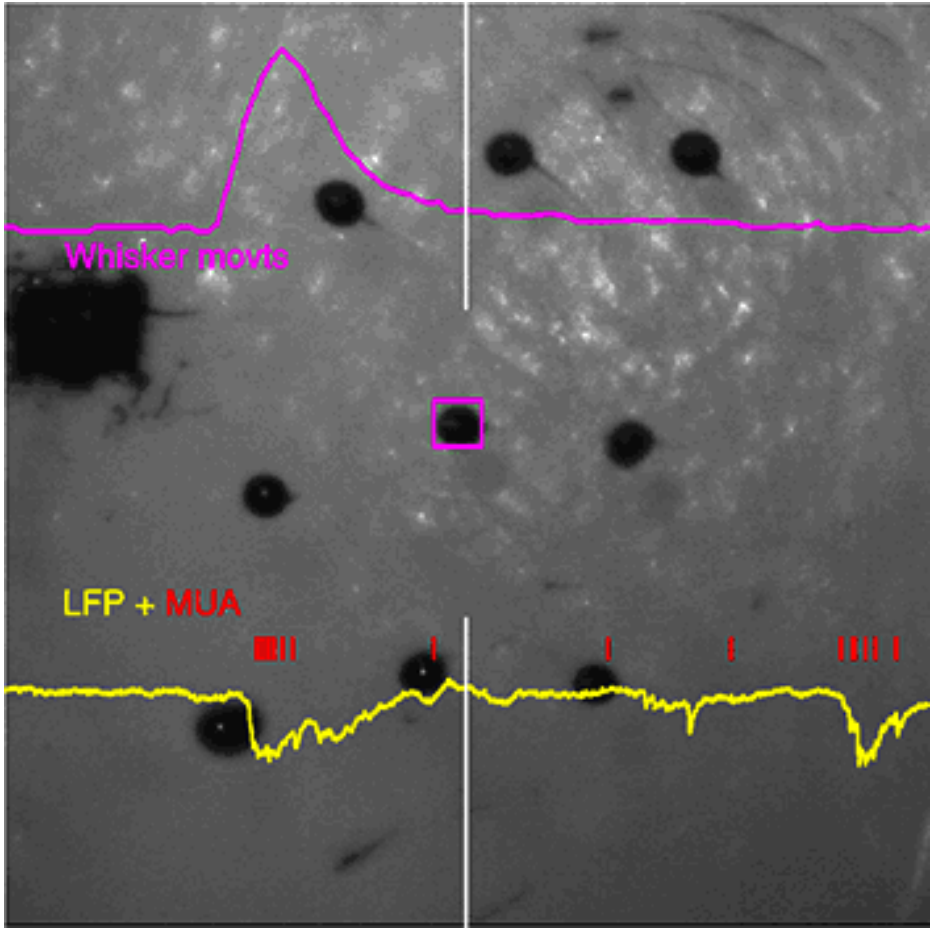

Movie 3. Artificial free whisker movement evoked by the electrical facial nerve stimulation. Magenta box represents $C 2$ whisker tip position. Magenta trace represents $C 2$ whisker movement vector amplitude. Yellow trace below represents LFP. Red vertical bars (and audio clicks) represent MUA in a C 2 barrel. White vertical line indicates the current frame. Recordings from a P7 rat. Video is displayed at $50 \mathrm{fps}$ frame rate (slowed down twofold).

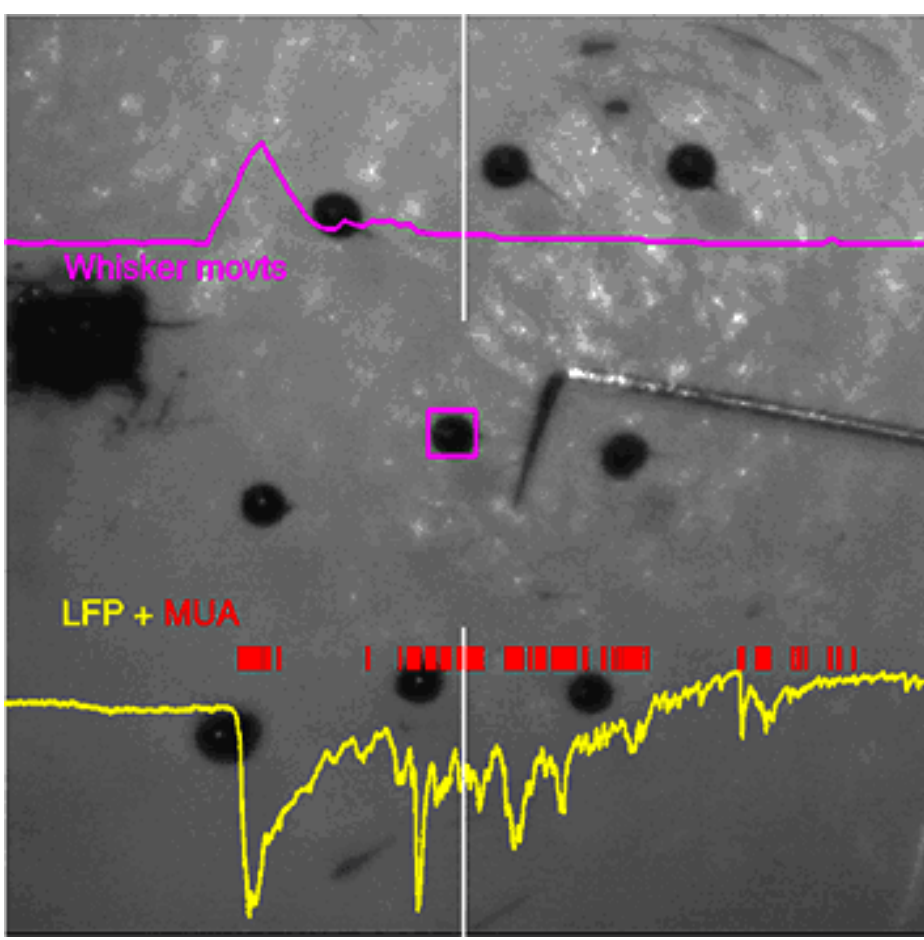

Movie 4. Artificial whisker movement with touch evoked by the electrical facial nerve stimulation. Object is placed on the $\mathrm{C} 2$ whisker path. Magenta box represents $\mathrm{C} 2$ whisker tip position. Magenta trace represents $\mathrm{C} 2$ whisker movement vector amplitude. Yellow trace below represents LFP. Red vertical bars (and audio clicks) represent MUA in a $\mathrm{C} 2$ barrel. White vertical line indicates the current frame. Recordings from a $\mathrm{P} 7 \mathrm{rat}$. Video is displayed at $50 \mathrm{fps}$ frame rate (slowed down twofold). 
A

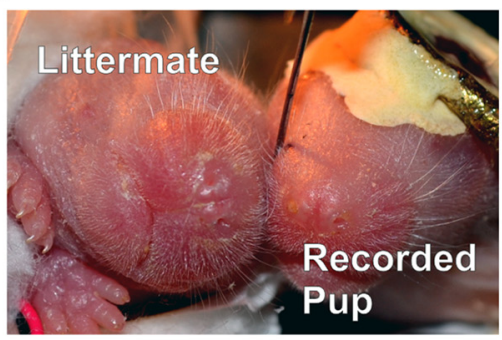

D

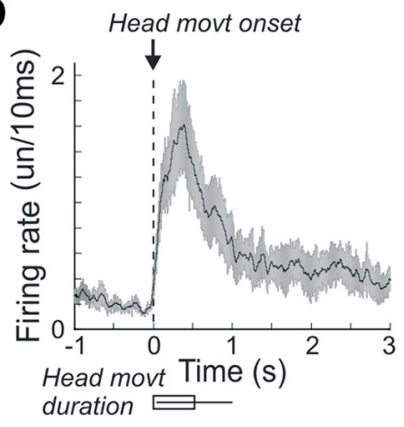

E

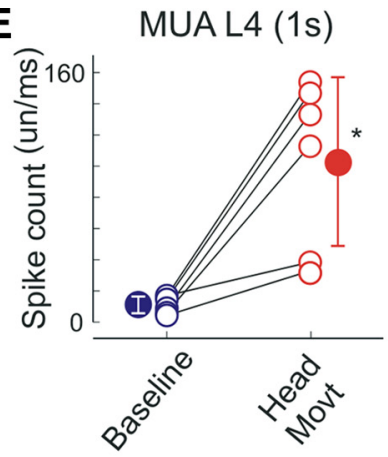

B
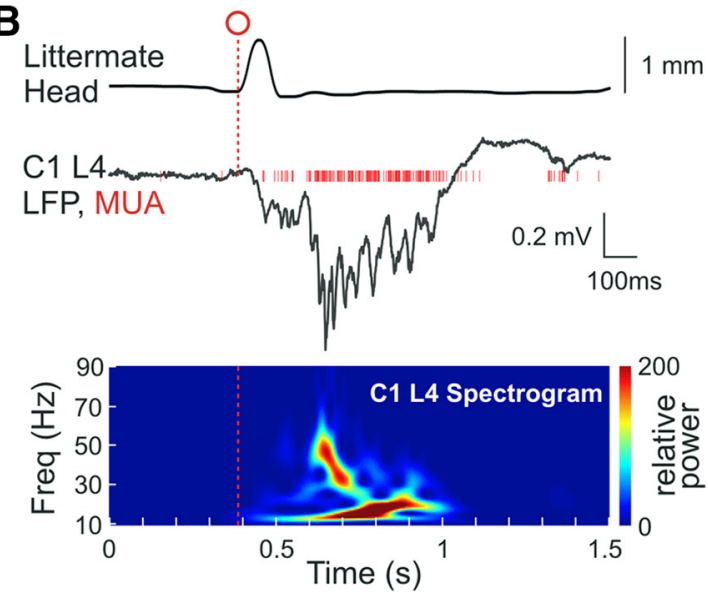

C

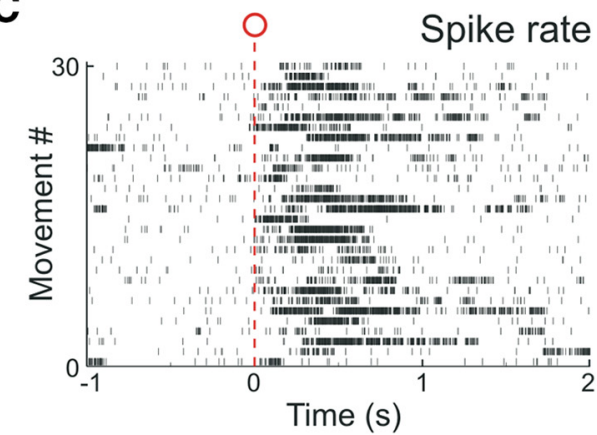

F
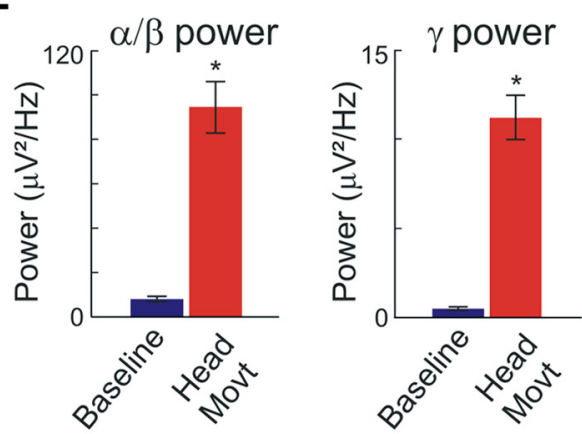

G

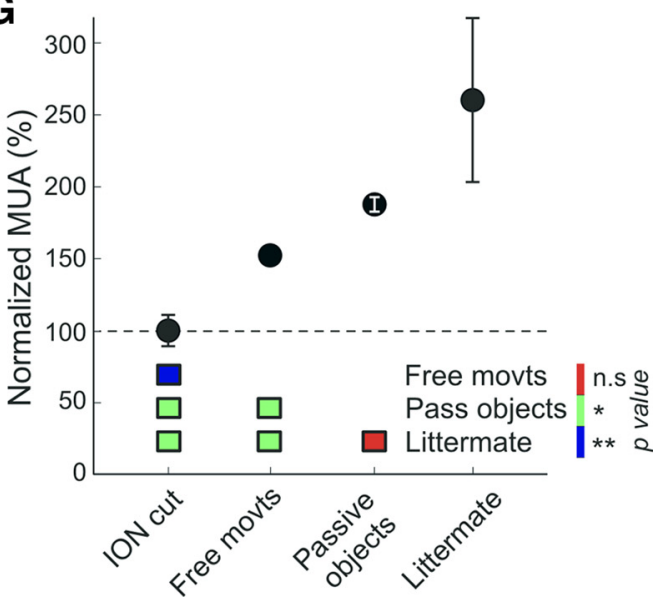

Figure 4. Activation of cortical barrels during littermate movements. $A$, Littermate (left) is placed snout to snoutpad to the recorded head-restrained P3 rat pup (right). Both animals are nonanesthetized. $\boldsymbol{B}$, Example response evoked by the littermate head movement (top) in the L 4 of a C 1 cortical column (middle) and the corresponding wavelet spectrogram (bottom). $\boldsymbol{C}$, Movement onset triggered spike raster plot in $\mathrm{L} 4$ of a $(1$ barrel column. $\boldsymbol{D}-\boldsymbol{F}$, Group data on $(\boldsymbol{D})$ littermate movement triggered $\mathrm{L} 4 \mathrm{MUA}$ time histograms (bottom, movements duration), $(\boldsymbol{E})$ total spike counts, and $(\boldsymbol{F})$ L4 LFP power in $\alpha-\beta$ and $\gamma$ frequency bands within a 1 s period before and after littermate's movements. $\boldsymbol{D}-\boldsymbol{F}$, Pooled data from six pairs of $P 2-P 6$ nonanesthetized rats. $\mathbf{G}, 0$ verall $L 4$ MUA frequency in the barrel cortex in nonanesthetized rat pups during free whisking, continuous PW contact with the passive objects (fur, mesh, anesthetized littermate), and a PW contact with the nonanesthetized littermate normalized to the level of activity after deafferentation by cutting the ION. Bottom, Color-coded $p$ value map for statistical comparisons between different conditions. ${ }^{*} p<0.05 ;{ }^{* *} p<0.01$. ns, Not significant.

rat pups' whiskers were in contact with the external objects, including littermates, mother, or nest lining $94 \pm 1 \%$ of time.

Next, we explored the impact of contact with the littermate on the activity in the barrel cortex. To achieve this aim, a littermate was placed in contact, snout to snout, to the recorded animal so that the PW was continuously touching the littermate (Fig. 4A). Movements of the recorded rat pup and littermate, detected from a change in the distance between the pups' snout contours, reliably evoked cortical responses as evidenced by an increase in L4 MUA (Fig. $4 B-E$; Movie 5) as well as in $\alpha-\beta$ and $\gamma$ power (Fig. $4 B, F)$. On average, L4 MUA increased from $11.2 \pm 5.6$ spikes/s of baseline to $102.9 \pm 54.1$ spikes/s within a $1 \mathrm{~s}$ time window after the movement onset ( $n=6$ pups; P2-P6; $p=0.016$; paired sample Wilcoxon signed rank test). Gamma and spindle burst power also showed an increase during littermate movements from $0.5 \pm 0.2 \mu \mathrm{V}^{2} / \mathrm{Hz}$ to $9.7 \pm 3.3 \mu \mathrm{V}^{2} / \mathrm{Hz}$, and from $8.8 \pm 2.7$ $\mu \mathrm{V}^{2} / \mathrm{Hz}$ to $94.6 \pm 35.5 \mu \mathrm{V}^{2} / \mathrm{Hz}$, respectively. To estimate the impact of tactile contact with the littermate on the total ongoing activity in the barrel cortex, we compared the mean L4 MUA from $30 \mathrm{~min}$ recording sessions of free whisker movements with recording sessions of whisker movements in continuous snoutto-snout contact with the littermate. The total count of L4 MUA under the conditions of contact with the littermate attained $19.9 \pm 7.4$ spikes/s, which was almost twofold higher than in the isolated animal (10.9 \pm 1.8 spikes/s; $n=4$ pups; P2-P6; $p=$ 0.029; Wilcoxon rank sum test; Fig. $4 G$ ). 


\section{Infraorbital nerve cut}

Finally, to estimate the level of spontaneous activity, supported by completely deafferented somatosensory networks, we cut the infraorbital nerve (ION), which conveys all sensory input from the whiskers. Recordings before and after the ION cut were performed in nonanesthetized animals under conditions of free whisker movements, whereas ION transection was performed under deep isoflurane anesthesia. We found that overall, L4 MUA reduced from $10.2 \pm 2.1$ spikes/s to $6 \pm 1$ spikes/s 1 h after the ION cut ( $n=7$ pups; P1-P6; Fig. 4G). The level of suppression of cortical activity to $66 \pm 7 \%$ of the control values after deafferentation obtained here in nonanesthetized animals was less pronounced than reported previously (Khazipov et al., 2004; Yang et al., 2009), where the activity was suppressed to $\sim 30 \%-50 \%$ of the control values, that probably reflects the use of anesthetics in previous studies. The level of L4 MUA suppression after the ION cut did not show any age dependence, either through the linear regression analysis $(r=0.15$; $p=0.74)$ or through the group data comparisons (P1-P2: $69 \pm 11 \% ; n=4$; and P5-P6: $61 \pm 10 \% ; n=3 ; p=0.59)$.

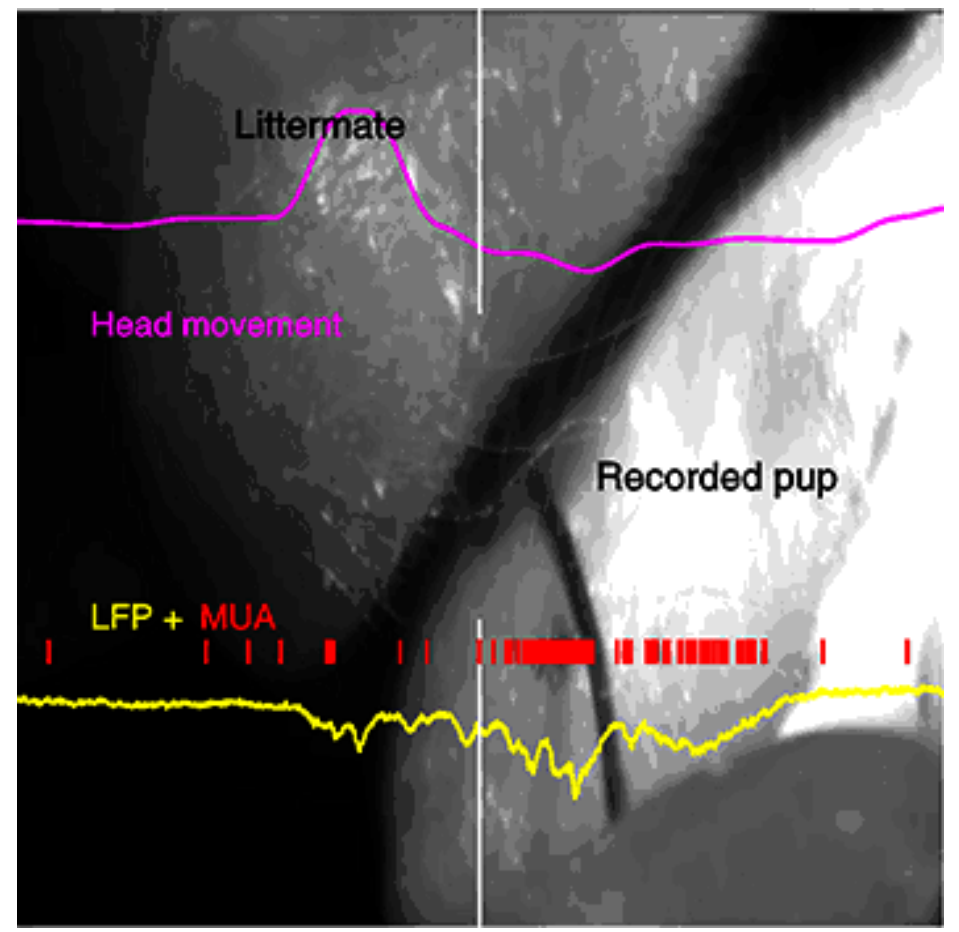

Movie 5. Littermate movements. Magenta trace represents a distance change between the littermates snouts. Yellow trace below represents LFP. Red vertical bars (and audio clicks) represent MUA in a D2 barrel. White vertical line indicates the current frame. Recordings from a P4 rat. Video is displayed at $15 \mathrm{fps}$ frame rate (slowed down twofold).

\section{Discussion}

In the present study, we aimed to estimate the relative contributions of different sensory stimuli in driving neuronal activity in the S1 barrel cortex of newborn rats under conditions mimicking the natural environment. Previously, two origins of the early somatosensory inputs have been suggested: passive whisker stimulation by the littermates and mother (Hanganu-Opatz, 2010; Erzurumlu and Gaspar, 2012) and sensory feedback from the primitive whisker movements (Tiriac et al., 2012). The relative contributions of these two mechanisms in driving the S1 cortex have remained largely unknown, however. The main finding of the present study is that spontaneous whisker movements and passive stimulation by the littermates play comparable roles in driving $\mathrm{S} 1$ activity in the neonatal rats. We also found that, whereas free whisker movements caused an elevation of cortical activity as reported previously (Tiriac et al., 2012), tactile feedback during the movements with touch significantly increased the efficiency of whisker movements to trigger cortical bursts. Tactile signals arising from the littermates' movements under conditions simulating the littermates' position in the home cage were also highly efficient in activating the barrel cortex. Comparison of various experimental conditions mimicking the natural environment (Fig. 4G) showed that tactile signals arising from whisker movements with touch and stimulation by the littermates, support: (1) a twofold higher level of cortical activity than that in an isolated animal, and (2) a threefold higher level of activity than that in a deafferented animal. Together, these results indicate that self-generated movements and passive stimulation provided by the littermates' movements cooperate, with comparable power, in driving $S 1$ cortical activity in newborn rats. The results also suggest that the natural environment significantly contributes to maintain physiological levels of S1 activity not only through direct stimulation by the littermates and mother but also by enabling tactile feedback during spontaneous movements.

In keeping with an onset of active whisking at $\sim$ P12 (Welker, 1964; Landers and Philip, 2006; Grant et al., 2012), we failed to observe any rapid active whisking in our experimental conditions in P4-P7 animals. However, a wide diversity of other intermittent whisker and mystacial pad movement patterns were observed during this period, including unidirectional brief and more complex movements similar to those reported by Blumberg and colleagues (Tiriac et al., 2012). Whisker movements in the neonatal rat pups showed the predominance of collective movements with the maximal movement correlations between adjacent whiskers in a row, and with the preferred movement directions of protraction and retraction, which also characterizes whisker movements in adult animals (Welker, 1964; Bermejo et al., 2002; Hill et al., 2008). Free whisker twitches were shown to cause an elevation of ventral posteromedial thalamic and S1 cortical activity indicating that reafferent sensory feedback acts as an efficient sensory signal (Tiriac et al., 2012) similar to the body twitches evoking spindle bursts in the $\mathrm{S} 1$ body regions (Khazipov et al., 2004). Our findings support these earlier findings but also show that cortical activation during whisker movements is significantly stronger if the whisker is touching an external object during movement, as evidenced by stronger activation of units and an increase in the spindle- and $\gamma$-bursts LFP power. A particularly robust difference in the efficacy of whisker movements with and without touch in triggering cortical activity was observed during artificially evoked movements evoked by stimulation of the motor nerves. In this set of experiments, artificial free whisker movements evoked only SEPs, whereas the same movements with 
touch evoked SEP + burst complexes with much stronger activation of cortical neurons. This difference between the results obtained with spontaneous and artificial movements may involve the inhibitory effect of urethane and thus elevated thalamocortical burst threshold in the experiments with the artificial movements.

The importance of tactile input in driving cortical activity during whisker movements, as shown here, is consistent with the findings made in adult animals, where presenting an object into the whisking path was shown to increase the number of responsive neurons in the trigeminal ganglion (Zucker and Welker, 1969; Szwed et al., 2003) and to increase the firing of neurons in the barrel cortex (Crochet et al., 2011). Moreover, CSD profiles of the responses evoked by artificial whisking, which revealed the main current sinks and activation of neurons in L4 of the barrel column during free whisking and whisking against the object, are in agreement with the results obtained in adult animals, where both the reafferent and the ex-afferent signals have been shown to be processed through the same lemniscal pathway (Moore et al., 2015). However, activation of cortical neurons during free whisker movements in neonatal rats, as observed here, is different from the results obtained in adult animals, where free whisking, associated with the induction of the cortical active state, did not alter the average firing frequency of principal neurons (Crochet and Petersen, 2006; Poulet and Petersen, 2008), the difference is likely due to the delayed development of the active states (Colonnese et al., 2010) and inhibitory intracortical mechanisms (Fagiolini et al., 2004; Daw et al., 2007; Minlebaev et al., 2011; Colonnese, 2014).

Our results provide, for the first time, the description of the two main sensory inputs to the barrel cortex operating under naturalistic conditions and both likely contributing to the activity-dependent thalamocortical developmental during the critical period. Although both inputs appeared to be efficient in triggering cortical activity, their physiological roles in development may differ. It has been previously shown that passive whisker stimulation, as in the case of the littermate touch, triggers thalamocortical oscillations in the barrel cortex with a repetitive sequential activation of the topographically aligned thalamic and cortical neurons to support the long-term potentiation at thalamocortical synapses (Minlebaev et al., 2011; An et al., 2012). Movement-evoked responses are also organized in oscillations, which are similar to the passive touch-evoked responses and thus create similar conditions for plasticity. However, because the activity bursts in the motor cortex may drive neonatal movements (An et al., 2014), they may, in addition, support synchronization in the developing sensorimotor circuits in an anti-Hebbian fashion, as has been previously demonstrated for the development of the nociceptive spinal cord networks (Petersson et al., 2003).

The results are also of interest for intersystems and interspecies comparisons. First, the environmental influence on the early operation of the developing somatosensory system (involving passive stimulation by the littermates and tactile contact during movements) makes it different from the visual and auditory systems, whose function during the early developmental period is primarily controlled by spontaneous activity at the sensory periphery insensitive to the external stimuli (for review, see Katz and Shatz, 1996; Blankenship and Feller, 2010; Hanganu-Opatz, 2010; Colonnese and Khazipov, 2012). Second, because similar stages of development in humans occur during the second half of gestation in utero, under the conditions of the limited external sensory stimulation (Clancy et al., 2001; Khazipov and Luhmann, 2006; Colonnese et al., 2010; Workman et al., 2013; Luhmann et al., 2016) (see also http://www.translatingtime.net/), we suggest that (1) spontaneous fetal movements and the resulting sensory feedback play more a significant role, than external stimulation in humans, and that (2) the importance of tactile feedback should be considered in the care of preterm neonates, who may have more freedom and less tactile feedback during their movements than the fetus in utero.

\section{References}

An S, Kilb W, Luhmann HJ (2014) Sensory-evoked and spontaneous gamma and spindle bursts in neonatal rat motor cortex. J Neurosci 34 : 10870-10883. CrossRef Medline

An S, Yang JW, Sun H, Kilb W, Luhmann HJ (2012) Long-term potentiation in the neonatal rat barrel cortex in vivo. J Neurosci 32:9511-9516. CrossRef Medline

Bermejo R, Vyas A, Zeigler HP (2002) Topography of rodent whisking: I. Two-dimensional monitoring of whisker movements. Somatosens Mot Res 19:341-346. CrossRef Medline

Blankenship AG, Feller MB (2010) Mechanisms underlying spontaneous patterned activity in developing neural circuits. Nat Rev Neurosci 11: 18-29. CrossRef Medline

Blumberg MS, Sokoloff G, Tiriac A, Del Rio-Bermudez C (2015) A valuable and promising method for recording brain activity in behaving newborn rodents. Dev Psychobiol 57:506-517. CrossRef Medline

Carvell GE, Simons DJ (1996) Abnormal tactile experience early in life disrupts active touch. J Neurosci 16:2750-2757. Medline

Clancy B, Darlington RB, Finlay BL (2001) Translating developmental time across mammalian species. Neuroscience 105:7-17. CrossRef Medline

Colonnese M, Khazipov R (2012) Spontaneous activity in developing sensory circuits: implications for resting state fMRI. Neuroimage 62:22122221. CrossRef Medline

Colonnese MT (2014) Rapid developmental emergence of stable depolarization during wakefulness by inhibitory balancing of cortical network excitability. J Neurosci 34:5477-5485. CrossRef Medline

Colonnese MT, Kaminska A, Minlebaev M, Milh M, Bloem B, Lescure S, Moriette G, Chiron C, Ben-Ari Y, Khazipov R (2010) A conserved switch in sensory processing prepares developing neocortex for vision. Neuron 67:480-498. CrossRef Medline

Crochet S, Petersen CC (2006) Correlating whisker behavior with membrane potential in barrel cortex of awake mice. Nat Neurosci 9:608-610. CrossRef Medline

Crochet S, Poulet JF, Kremer Y, Petersen CC (2011) Synaptic mechanisms underlying sparse coding of active touch. Neuron 69:1160-1175. CrossRef Medline

Crocker-Buque A, Brown SM, Kind PC, Isaac JT, Daw MI (2015) Experience-dependent, layer-specific development of divergent thalamocortical connectivity. Cereb Cortex 25:2255-2266. CrossRef Medline

Daw MI, Ashby MC, Isaac JT (2007) Coordinated developmental recruitment of latent fast spiking interneurons in layer IV barrel cortex. Nat Neurosci 10:453-461. CrossRef Medline

Erzurumlu RS, Gaspar P (2012) Development and critical period plasticity of the barrel cortex. Eur J Neurosci 35:1540-1553. CrossRef Medline

Fagiolini M, Fritschy JM, Löw K, Möhler H, Rudolph U, Hensch TK (2004) Specific GABAA circuits for visual cortical plasticity. Science 303: 1681-1683. CrossRef Medline

Feldman DE, Brecht M (2005) Map plasticity in somatosensory cortex. Science 310:810-815. CrossRef Medline

Feldman DE, Knudsen EI (1998) Experience-dependent plasticity and the maturation of glutamatergic synapses. Neuron 20:1067-1071. CrossRef Medline

Fox K (1992) A critical period for experience-dependent synaptic plasticity in rat barrel cortex. J Neurosci 12:1826-1838. Medline

Freeman JA, Nicholson C (1975) Experimental optimization of current source-density technique for anuran cerebellum. J Neurophysiol 38: 369-382. Medline

Gramsbergen A, Schwartze P, Prechtl HF (1970) The postnatal development of behavioral states in the rat. Dev Psychobiol 3:267-280. CrossRef Medline

Grant RA, Mitchinson B, Prescott TJ (2012) The development of whisker control in rats in relation to locomotion. Dev Psychobiol 54:151-168. CrossRef Medline 
Hanganu-Opatz IL (2010) Between molecules and experience: role of early patterns of coordinated activity for the development of cortical maps and sensory abilities. Brain Res Rev 64:160-176. CrossRef Medline

Higashi S, Hioki K, Kurotani T, Kasim N, Molnár Z (2005) Functional thalamocortical synapse reorganization from subplate to layer IV during postnatal development in the reeler-like mutant rat (shaking rat Kawasaki). J Neurosci 25:1395-1406. CrossRef Medline

Hill DN, Bermejo R, Zeigler HP, Kleinfeld D (2008) Biomechanics of the vibrissa motor plant in rat: rhythmic whisking consists of triphasic neuromuscular activity. J Neurosci 28:3438-3455. CrossRef Medline

Hoerder-Suabedissen A, Molnár Z (2015) Development, evolution and pathology of neocortical subplate neurons. Nat Rev Neurosci 16:133-146. CrossRef Medline

Isaac JT, Crair MC, Nicoll RA, Malenka RC (1997) Silent synapses during development of thalamocortical inputs. Neuron 18:269-280. CrossRef Medline

Kanold PO, Luhmann HJ (2010) The subplate and early cortical circuits. Annu Rev Neurosci 33:23-48. CrossRef Medline

Katz LC, Shatz CJ (1996) Synaptic activity and the construction of cortical circuits. Science 274:1133-1138. CrossRef Medline

Khazipov R, Luhmann HJ (2006) Early patterns of electrical activity in the developing cerebral cortex of humans and rodents. Trends Neurosci 29: 414-418. CrossRef Medline

Khazipov R, Sirota A, Leinekugel X, Holmes GL, Ben-Ari Y, Buzsáki G (2004) Early motor activity drives spindle bursts in the developing somatosensory cortex. Nature 432:758-761. CrossRef Medline

Landers M, Philip Zeigler H (2006) Development of rodent whisking: trigeminal input and central pattern generation. Somatosens Mot Res 23: 1-10. CrossRef Medline

Luhmann HJ, Sinning A, Yang JW, Reyes-Puerta V, Stüttgen MC, Kirischuk S, Kilb W (2016) Spontaneous neuronal activity in developing neocortical networks: from single cells to large-scale interactions. Front Neural Circuits 10:40. CrossRef Medline

Minlebaev M, Ben-Ari Y, Khazipov R (2007) Network mechanisms of spindle burst oscillations in the neonatal rat barrel cortex in vivo. J Neurophysiol 97:692-700. CrossRef Medline

Minlebaev M, Ben-Ari Y, Khazipov R (2009) NMDA receptors pattern early activity in the developing barrel cortex in vivo. Cereb Cortex 19:688-696. CrossRef Medline

Minlebaev M, Colonnese M, Tsintsadze T, Sirota A, Khazipov R (2011) Early gamma oscillations synchronize developing thalamus and cortex. Science 334:226-229. CrossRef Medline

Mitra PP, Pesaran B (1999) Analysis of dynamic brain imaging data. Biophys J 76:691-708. CrossRef Medline

Mitrukhina O, Suchkov D, Khazipov R, Minlebaev M (2014) Imprecise whisker map in the neonatal rat barrel cortex. Cereb Cortex 25:34583467. CrossRef Medline

Mohns EJ, Blumberg MS (2010) Neocortical activation of the hippocampus during sleep in infant rats. J Neurosci 30:3438-3449. CrossRef Medline

Moore JD, Mercer Lindsay N, Deschênes M, Kleinfeld D (2015) Vibrissa self-motion and touch are reliably encoded along the same somatosensory pathway from brainstem through thalamus. PLoS Biol 13:e1002253. CrossRef Medline

Petersson P, Waldenström A, Fåhraeus C, Schouenborg J (2003) Spontaneous muscle twitches during sleep guide spinal self-organization. Nature 424:72-75. CrossRef Medline

Poulet JF, Petersen CC (2008) Internal brain state regulates membrane potential synchrony in barrel cortex of behaving mice. Nature 454:881-885. CrossRef Medline

Simons DJ, Land PW (1987) Early experience of tactile stimulation influences organization of somatic sensory cortex. Nature 326:694-697. CrossRef Medline

Szwed M, Bagdasarian K, Ahissar E (2003) Encoding of vibrissal active touch. Neuron 40:621-630. CrossRef Medline

Tiriac A, Blumberg MS (2016) The case of the disappearing spindle burst. Neural Plast 2016:8037321. CrossRef Medline

Tiriac A, Uitermarkt BD, Fanning AS, Sokoloff G, Blumberg MS (2012) Rapid whisker movements in sleeping newborn rats. Curr Biol 22: 2075-2080. CrossRef Medline

Tiriac A, Sokoloff G, Blumberg MS (2015) Myoclonic twitching and sleepdependent plasticity in the developing sensorimotor system. Curr Sleep Med Rep 1:74-79. CrossRef Medline

Van der Loos H, Woolsey TA (1973) Somatosensory cortex: structural alterations following early injury to sense organs. Science 179:395-398. CrossRef Medline

Welker WI (1964) Analysis of sniffing of the albino rat. Behaviour 22: 223-244. CrossRef

Workman AD, Charvet CJ, Clancy B, Darlington RB, Finlay BL (2013) Modeling transformations of neurodevelopmental sequences across mammalian species. J Neurosci 33:7368-7383. CrossRef Medline

Yang JW, Hanganu-Opatz IL, Sun JJ, Luhmann HJ (2009) Three patterns of oscillatory activity differentially synchronize developing neocortical networks in vivo. J Neurosci 29:9011-9025. CrossRef Medline

Yang JW, An S, Sun JJ, Reyes-Puerta V, Kindler J, Berger T, Kilb W, Luhmann HJ (2013) Thalamic network oscillations synchronize ontogenetic columns in the newborn rat barrel cortex. Cereb Cortex 23:1299-1316. CrossRef Medline

Zucker E, Welker WI (1969) Coding of somatic sensory input by vibrissae neurons in the rat's trigeminal ganglion. Brain Res 12:138-156. CrossRef Medline 